\title{
MEDIÇÕES IN SITU DA CONCENTRAÇÃO DE CO 2 EM UM RESERVATÓRIO TROPICAL USANDO LI-7500A E UMA BOIA METEOROLÓGICA
}

\author{
Roseilson do Vale ${ }^{1}$, Raoni Santana ${ }^{1}$, Júlio Tota ${ }^{2}$, Newton Lima ${ }^{1}$ \\ ${ }^{1}$ Doutorando em Clima e Ambiente - INPA/UEA \\ ${ }^{2}$ Universidade Federal do Oeste do Pará - UFOPA
}

\section{RESUMO}

Medidas da concentração do ciclo diário de $\mathrm{CO}_{2}$ foram realizadas sobre a superfície do lago da Usina Hidrelétrica de Balbina/AM. As medidas foram realizadas com analisador de gás por infravermelho da marca Licor, modelo 7500A. Os dados de concentração de $\mathrm{CO}_{2}$ foram analisados e comparados com dados meteorológicos de umidade relativa e precipitaçãode uma boia instalada com uma estação HOBO U-30, localizada no mesmo lago. Este estudo revela um aumento da concentração de $\mathrm{CO}_{2}$ no período noturno.

Palavras-chave: concentração de $\mathrm{CO}_{2}$, umidade relativa e precipitação.

\begin{abstract}
Measures the concentration of the daily cycle of $\mathrm{CO}_{2}$ were carried out on the surface of the lake of the Balbina Hydroelectric Plant/AM. The measurements were performed with infrared gas analyzer brand Licor, model 7500A. The $\mathrm{CO}_{2}$ concentration data were analyzed and compared with meteorological data from a buoy fitted with a HOBO U-30 station, located in the same lake. This study reveals an increase in the concentration of $\mathrm{CO}_{2}$ at night.
\end{abstract}

Key-words: $\mathrm{CO}_{2}$ concentration, relative humidity and rainfall.

\section{INTRODUÇÃO}

Estudos recentes das últimas duas décadas têm mostrado que os lagos e reservatórios têm desempenhado um papel fundamental no balanço regional e global de carbono (Richey et al., 2002). Na Amazônia, o fluxo de $\mathrm{CO}_{2}$ proveniente de águas 
interiores, é comparável a taxa de carbono armazenado nas árvores das florestas amazônicas (Phillips et al., 1998) e muito maior do que o carbono exportado pela Amazônia para os oceanos (Richey et al., 2002). Este trabalho analisou a concentração de $\mathrm{CO}_{2}$ sobre a superfície de um lago de um reservatório da UHE-Balbina/AM e com alguns dados de uma boia meteorológica como umidade relativa $(\mathrm{RH})$ e precipitação.

\section{MATERIAL E MÉTODO}

Os dados utilizados para a análise de $\mathrm{CO}_{2}$ e precipitação foram coletados nos dias 18 e 19 de julho e para umidade relativa e temperatura de 15 a 20 de julho de 2013, no lago do reservatório da UHE-Balbina (59²80’5000’' W, $1^{\circ} 530$ '2500’'; S) (Figura 1.a). Os dados de concentração de $\mathrm{CO}_{2}$ foram obtidos do analisador de gás por infravermelho LiCor-7500A (Figura 1.c) e dados de RH e precipitação da boia meteorológica preparada com uma estação HOBO U-30 que enviava dados via GSM para o servidor HOBOlink da Rede de Mudanças Climáticas da Amazônia (Remclam)/UEA (Figura 1.b).

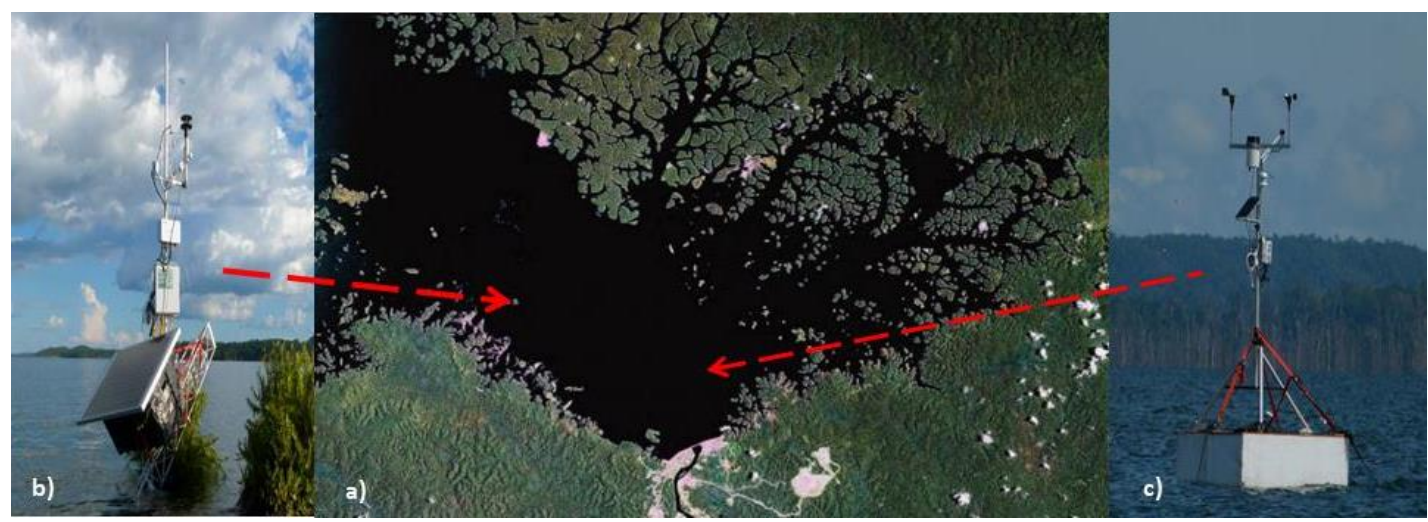

Figura 1. a)Instrumentação montada sobre o lago do reservatório da UHE-Balbina. b) Torre equipada com anemômetro sônico de três eixos (CSAT-3, Campbel), analisador de gás por infravermelho (modelo 7500A-LiCor) e sônico 2D (Gill c) Boia meteorológica equipada com uma estação HOBO com funcionamento telemétrico

Os dados de concentração de $\mathrm{CO}_{2}$ foram amostrados a uma taxa de $10 \mathrm{~Hz}$. Para os dados de precipitação calculou-se o acumulado horário. Os dados de umidade relativa e temperatura foram amostrados a cada 5 minutos e retirada a média horária. 


\section{RESULTADOS}

A Figura 2 apresenta os resultados obtidos para a concentração de $\mathrm{CO}_{2}$ e precipitação. Durante o dia as concentrações de $\mathrm{CO}_{2}$ permaneceram praticamente constantes, em torno de $400 \mathrm{ppm}$. No entanto, durante a noite ocorreu um acumulo de $\mathrm{CO}_{2}$ sobre a superfície do lago entre 450 e $500 \mathrm{ppm}$. Os eventos de chuva foram bem localizados com um máximo às $17 \mathrm{~h}(\sim 35 \mathrm{~mm})$. As amplitudes de temperatura e RH foram de $23^{\circ}-31^{\circ} \mathrm{C}$ e $68 \%-98 \%$, respectivamente.
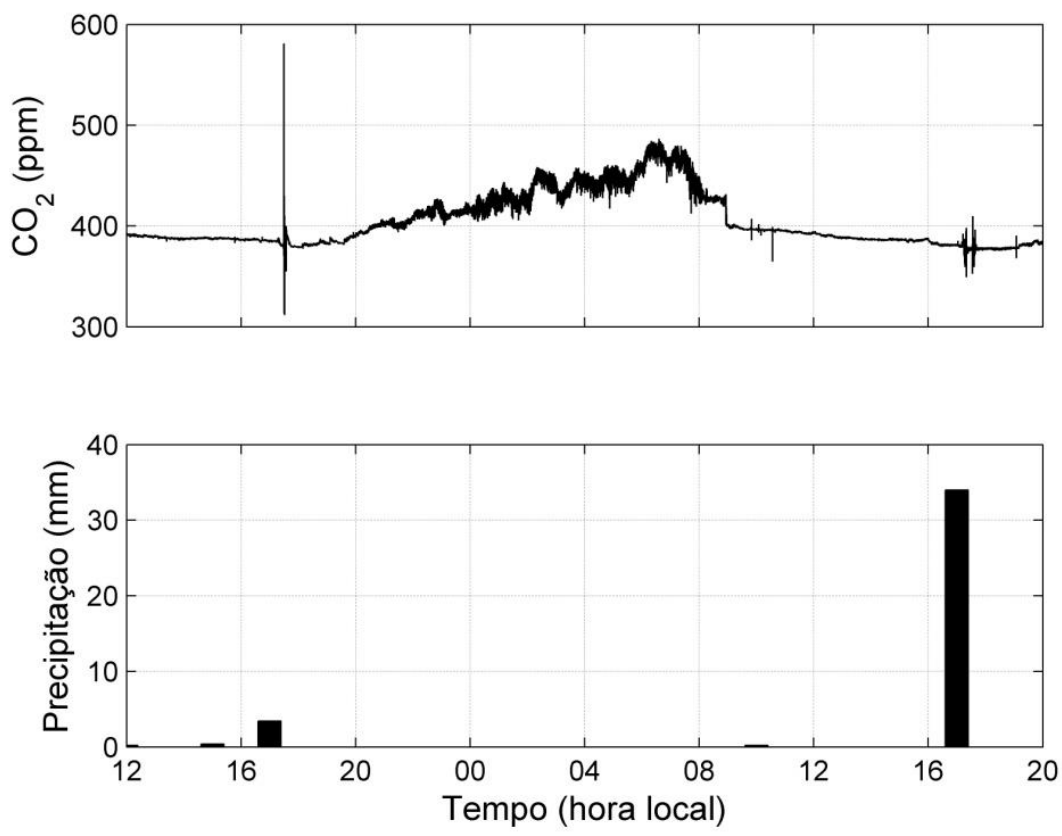

Figura 2. Concentração de $\mathrm{CO}_{2} \mathrm{em}$ ppm (acima) e precipitação em mm (abaixo) para os dias 18 e 19 de julho no lago do reservatório da UHE-Balbina. 


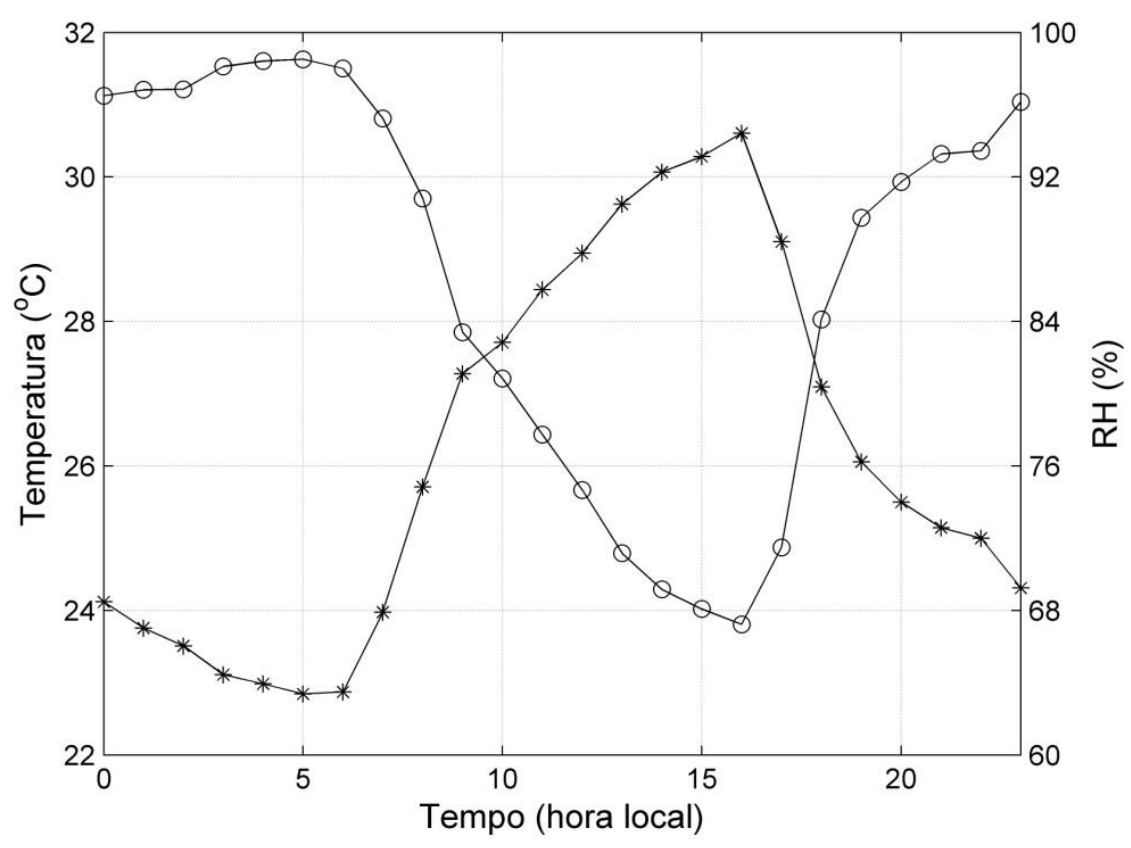

Figura 3. Umidade relativa $(\%)$ versus temperatura $\left({ }^{\circ} \mathrm{C}\right)$ referente aos dias 15 a 20 de julho no lago do reservatório da UHE-Balbina.

\section{DISCUSSÃO}

O fluxo de $\mathrm{CO}_{2}$ depende principalmente do gradiente de concentração entre a superfície da água e o ar e a transferência física ou energia turbulenta nesta interface (MacIntyre et al. 1995). Desse modo, o acumulo de $\mathrm{CO}_{2}$ na superfície do lago a noite se dá devido à diminuição ou ausência de turbulência. Uma vez que em lagos a fonte dominante de turbulência na superfície da camada limite aquosa é controlada pelo vento (Cole e Caraco, 1998). A parit das $18 \mathrm{~h}$ é visível a formação de nevoeiros sobre a superfície do lago devido aos altos valores de RH e baixos de temperatura. Na figura 2, vemos claramente picos na concentração do $\mathrm{CO}_{2}$ relacionado com chuva, isto ocorre devido a erros da leitura do sensor em dias de chuva.

\section{CONCLUSÕES}

$\mathrm{O}$ aumento da concentração de $\mathrm{CO}_{2}$ no período da noite está relacionado a diminuição da turbulência e ao resfriamento da camada do ar próximo a superfície do lago e da camada limite aquosa. 


\section{AGRADECIMENTOS}

A Fundação de Amparo a Pesquisa no Amazonas - FAPEAM, a CAPES e a Adry Trindade pelas fotos.

\section{BIBLIOGRAFIA}

COLE, J. J., CARACO, N.F. Atmospheric Exchange of carbono dioxide in a low-wind oligotrophic lake measured by the addition of SF6. Limnol. Oceanogr. 43, 647-656, 1998.

MACINTYRE, S., WANNINKHOF, R., CHANTON, J.P. Trace gas exchange across the air-water interface in freshwaters and coastal marine environments. In: Matson, P.A., Harris, R.C. (Eds.), Biogenic Trace Gases: Measuring Emissions from Soil and Water. Blackwell, pp. 52-97, 1995.

PHILlIPS, O.L.; MALHI, Y.; HIGUCHI, N.; LAURANCE, W.F.; NÚÑEZ, P.V.; VÁSQUEZ, R.M.; LAURANCE, S.G.; FERREIRA, L.V.; STERN, M.; BROWN, S.; GRACE, J. Changes in the carbon balance of tropical forests: evidence from long-term plots. Science, v. 282, pp. 439-442, 1998.

RICHEY, J.E; MELACK, J.M.; AUFDENKAMPE, A.K.; BALLESTER, V.M.; HESS, L. From water to the atmosphere: carbon dioxide evasion from the Amazon River system. Nature, London, v. 416, p. 617 - 620, 2002. 